\title{
A case of inferior alveolar nerve encircling the arteria maxillaris
}

\author{
Unnathi Nayak ${ }^{1}$, Rajanigandha Vadgaonkar ${ }^{2}$, Mangala M. Pai ${ }^{2}$, B.V. Murlimanju ${ }^{2}$ \\ ${ }^{1}$ Third Semester MBBS Student, ${ }^{2}$ Department of Anatomy, Kasturba Medical College Mangalore, Manipal Academy of Higher Education, Manipal, \\ Karnataka, India
}

\begin{abstract}
Here we report a case of inferior alveolar nerve (IAN), which had variability in its formation. IAN was formed by dual roots, which were branching out from the posterior division of mandibular nerve. The observed roots were forming a loop around the pterygoid part of arteria maxillaris (MA). One of the roots was superficial to the MA and the other was deep to it. It is believed that this type of morphological variation in the formation of IAN can have clinial implications, which include compression by adjacent structures and nerve entrapment. The knowledge of this variation is important to anaesthesiologists and dentists, while administering local anaesthesia. This is also enlightening to the maxillofacial surgeons, neurologists and radiologists.
\end{abstract}

Key words: Inferior alveolar nerve, Mandibular nerve, Nerve compression syndromes

Received September 10, 2019; Revised November 4, 2019; Accepted November 22, 2019

\section{Introduction}

It is essential for the maxillofacial surgeons, radiologists and dentists to have a sound knowledge about anatomical variations at the infratemporal fossa as this region is hard to access surgically [1]. It was reported that the variations of mandibular nerve and arteria maxillaris (MA) may lead to compression of neurovascular contents causing symptoms of altered sensorium and pain in the craniofacial region [2]. The lingual and inferior alveolar nerve (IAN) are the chief branches of the posterior division of mandibular nerve in the infratemporal fossa. The MA and pterygoid venous plexus are the important vessels in this region. The face receives sensory innervation from the branches of fifth cranial nerve, mandibular nerve being one among them. Mandibular nerve gives the IAN, which supplies the mandibular teeth.

\section{Corresponding author:}

B.V. Murlimanju (iD

Department of Anatomy, Kasturba Medical College Mangalore, Manipal Academy of Higher Education, Manipal 575004, Karnataka, India

E-mail: flutemist@gmail.com
Morphological deviations in the infratemporal region and difficulty in identifying the anatomical landmarks have been reported to have resulted in ineffective nerve blocks [35]. There are few reports of accessory mandibular foramina and accessory IANs available [6], the same about double roots forming the IAN are rarely reported. Here we report an unusual case of two roots which are forming the IAN in a female cadaver.

\section{Case Report}

We report a variation of right sided infratemporal region in an embalmed female cadaver aged approximately 70 years (Fig. 1). The IAN was found to emerge as double roots from the posterior division of mandibular nerve. The duo formed a loop around the pterygoid part of MA. One of the pair was superficial (root 1), while the other (root 2) coursed deep to the MA (Fig. 1). The superficial root of IAN measured 14 $\mathrm{mm}$ and the deep root was $20 \mathrm{~mm}$ in length. Later these two roots joined to form the IAN. The IAN accompanied its associated vessel to enter the mandibular foramen as usual. The nerve to mylohyoid was seen arising $10 \mathrm{~mm}$ below the 


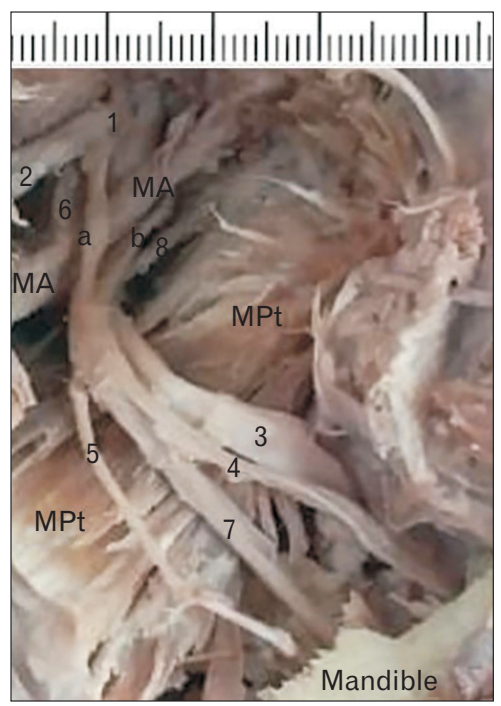

Fig. 1. Cadaveric specimen showing the variations observed in the right infra-temporal fossa of a female cadaver. 1, posterior division of mandibular nerve; 2 , ATN; 3 , lingual nerve; 4 , IAN; 5 , nerve to mylohyoid; 6 , middle meningeal artery; 7 , inferior alveolar artery; 8 , artery to medial pterygoid; a, superficial root of IAN; b, deep root of IAN; ATN, auriculotemporal nerve; IAN, inferior alveolar nerve; MA, arteria maxillaris; MPt, medial pterygoid.

formation of IAN. The artery to medial pterygoid (AMPt) was passing deep to both the roots of IAN and it measured $15 \mathrm{~mm}$ before it reached medial to lateral pterygoid plate and passed deep to it. This AMPt was coursing between the deep root of IAN and lingual nerve (LN) (Fig. 1). The MA measured $69 \mathrm{~mm}$ at the infratemporal region. The auriculotemporal nerve (ATN) arose as a solitary root and was found to be unusually thick (Fig. 1). The ATN was running superficial to the arteria meningea media. The $\mathrm{LN}$ was originating deeper to the pterygoid part of internal MA. The neurovascular variations observed in this case are schematically represented in Fig. 2.

\section{Discussion}

According to Wolf et al. [6], if the MA is enclosed between the nerves, it can lead to complications. It is also possible that pulsating MA can compress the surrounding nerves leading to symptoms like pain, tingling and numbness in their area of distribution [6, 7]. Nerve compression has been reported to trigger recurrent attacks of facial pain and is among the causes of trigeminal neuralgia [6]. The MA can also be injured during the nerve block procedures, if they are looped by the nerve roots. This may cause severe bleeding and he-

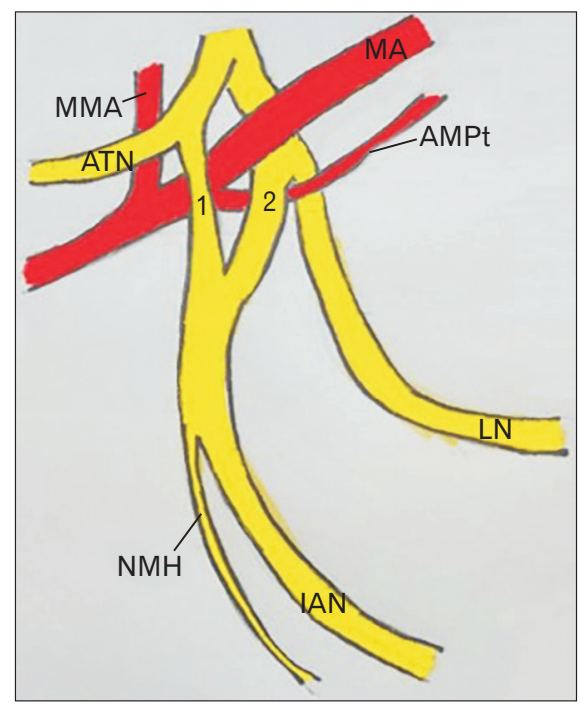

Fig. 2. Schematic diagram showing the variations observed in the present case. 1, superficial root of IAN; 2, deep root of IAN; AMPt, artery to medial pterygoid; ATN, auriculotemporal nerve; IAN, inferior alveolar nerve; LN, lingual nerve; MA, arteria maxillaris; MMA, middle meningeal artery; $\mathrm{NMH}$, nerve to mylohyoid.

matoma formation. Either of the roots of IAN as observed in the present case can be compressed by MA. It can cause tic douloureux and altered sensation of gingival mucosa $[8$, 9]. Chen et al. [10] opined that the surgical decompression is the best alleviate for the trigeminal neuralgia due to arterial compression.

Double formative roots of the IAN was reported previously by Wolf et al. [6] and Khan et al. [11]. These variations are analogous to the present observation in the present study. On the other hand, Sumalatha et al. [7], Pai et al. [12] and Quadros et al. [13] reported cases of multiple roots forming the IAN. If there are multiple nerve roots, the chances and effects of nerve compression are doubled. Dodd et al. [14] reported that perineural spread of tumours are often overlooked by operating surgeons. Primary and secondary metastatic carcinomas can occur in the infratemporal fossa. Pretterklieber et al. [15] reported that, in $4.9 \%$ of their cases, the MA was piercing the IAN. They also observed that in one case, IAN and LN, both had two roots because of perforation by the MA. A unique case was documented by Kalra et al. [16] where there was anomalous coexistence of binary roots of ATN, which passed superficial to the arteria meningea media. Gülekon et al. [17] observed that $50 \%$ of their specimens had single root of ATN. Here also a similar occurrence of solitary root was noted. Ortug and Moriggl [18] observed a condition in which MA was perforating the LN. 
Babu amd Thomas [19] reported an interesting finding of the MA which was passing inside the nervus auriculotemporalis formation. Anatomical relationships amid the neurovascular structures, muscles and their associated bony articulations in the infratemporal fossa favours high occurrence of various entrapment syndromes. Since it is not uncommon to find variations in the infratemporal fossa, the clinicians should be aware of the possible variations along with the normal anatomy. This will help them to avoid misinterpretations and subsequent complications. Also, Pai et al. [12] speculate that these types of neurovascular association variations should be considered in the future radiological and clinical studies.

During the development, mandibular nerve and its branches are derived from the migration of neural crest cells at the rostral end of the embryo. This migration occurs anteriorly through the mesoderm of the first pharyngeal arch. This happens due to interactions of multiple cell matrices [20] along with chemo- repulsions $[21,22]$. Sometimes, this neural crest cell migration is prevented by factors which are released by the caudal somites $[23,24]$. Since there are separate pathways for the development of motor and sensory fibres, there is a possibility of occurrence of two nerve bundles, explaining the developmental basis of the two roots of IAN, which is observed in this cadaver.

The myoblastic cells of the pterygoid mass will form a vascular arcade, which later forms the MA. Initially the stapedial artery supplies this network, but later taken over by the external carotid artery. During this taking over, most of the vascular network regresses except for few vessels, which forms MA. If there are variant nerve loops, these persistent vessels may remain in these loops. This leads to the development of MA inside the nerve loop $[25,26]$. This could be the reason for the observed variation of the MA encircled by the IAN- superficial and deep roots.

It was reported that, incomplete fusion of nerves may lead to accessory foramina in the mandible [27]. Lee et al. [28] from their histoloical observations reported that, the intramandibular course of IAN has a larger trunk, which consists of two separate nerve bundles. These bundles are of mental and dental nerves, and covered with the same epineurium. The mental nerve gets separated from it near the premolar region [28], because the mandibular canal splits into the mental and incisive canals near the premolar area [29]. Here the present study observed that there were two roots of IAN being observed in the infratemporal fossa. This could be hypothesized that these two roots are of dental and mental nerves, which are formed separately from the posterior division of mandibular nerve. These roots have joined near the mandibular foramen to have a solitary intra-mandibular course and might have split later again near the mental foramen.

In conclusion, variations in the branching pattern of mandibular nerve and their aberrent communications have an upper hold in understanding the effectiveness of nerve blocks and complications in dental surgery and regional anesthesia. It must be taken into account that the failure of anesthetic effect upon its administration during regional surgeries can also be due to the variations in the structures pertaining to the infratemporal fossa. This necessitates adopting alternative methods of regional aneasthesia. The complex anatomical relationships between the neurovascular structures in the infratemporal fossa favours increased incidence of nerve entrapments as well. We opine that such relevant variations should be included in the list of causative factors of disorders like trigeminal neuralgia.

\section{ORCID}

Unnathi Nayak: https://orcid.org/0000-0003-1900-7192

Rajanigandha Vadgaonkar:

https://orcid.org/0000-0001-5577-495X

Mangala M. Pai: https://orcid.org/0000-0001-6995-5807

B.V. Murlimanju: https://orcid.org/0000-0003-1248-8296

\section{Author Contributions}

Conceptualization: RV. Data acquisition: UN. Data analysis or interpretation: BVM. Drafting of the manuscript: BVM. Critical revision of the manuscript: MMP. Approval of the final version of the manuscript: all authors.

\section{Conflicts of Interest}

No potential conflict of interest relevant to this article was reported.

\section{References}

1. Piagkou M, Demesticha T, Skandalakis P, Johnson EO. Functional anatomy of the mandibular nerve: consequences of nerve injury and entrapment. Clin Anat 2011;24:143-50. 
2. Anil A, Peker T, Turgut HB, Gülekon IN, Liman F. Variations in the anatomy of the inferior alveolar nerve. Br J Oral Maxillofac Surg 2003;41:236-9.

3. Fleury AA. Local anesthesia failure in endodontic therapy: the acute inflammation factor. Compendium 1990;11:210, 212, 214 passim.

4. Wong MK, Jacobsen PL. Reasons for local anesthesia failures. J Am Dent Assoc 1992;123:69-73.

5. Vreeland DL, Reader A, Beck M, Meyers W, Weaver J. An evaluation of volumes and concentrations of lidocaine in human inferior alveolar nerve block. J Endod 1989;15:6-12.

6. Wolf KT, Brokaw EJ, Bell A, Joy A. Variant inferior alveolar nerves and implications for local anesthesia. Anesth Prog 2016; 63:84-90.

7. Sumalatha S, Kotian SR, Thodeti H, Pandey AK, Fernandez RK, Nayak VS. Variations of the lingual and inferior alveolar nerves and their anomalous relationship with the maxillary artery. Eur J Anat 2018;22:403-10.

8. Krmpotić-Nemanić J, Vinter I, Hat J, Jalsovec D. Mandibular neuralgia due to anatomical variations. Eur Arch Otorhinolaryngol 1999;256:205-8.

9. Calvin WH, Loeser JD, Howe JF. A neurophysiological theory for the pain mechanism of tic douloureux. Pain 1977;3:147-54.

10. Chen GQ, Wang XS, Wang L, Zheng JP. Arterial compression of nerve is the primary cause of trigeminal neuralgia. Neurol Sci 2014;35:61-6.

11. Khan MM, Darwish HH, Zaher WA. Perforation of the inferior alveolar nerve by the maxillary artery: an anatomical study. $\mathrm{Br}$ J Oral Maxillofac Surg 2010;48:645-7.

12. Pai MM, Swamy RS, Prabhu LV. A variation in the morphology of the inferior alveolar nerve with potential clinical significance. Biomed Int 2010;1:93-5.

13. Quadros LS, Roy PA, D'souza AS. Inferior alveolar nerve with multiple roots. Br Biomed Bull 2014;2:26-30.

14. Dodd GD, Dolan PA, Ballantyne AJ, Ibanez ML, Chau P. The dissemination of tumors of the head and neck via the cranial nerves. Radiol Clin North Am 1970;8:445-61.

15. Pretterklieber ML, Skopakoff C, Mayr R. The human maxillary artery reinvestigated: I. topographical relations in the infratemporal fossa. Acta Anat (Basel) 1991;142:281-7.
16. Kalra S, Thamke S, Khandelwal A. An undocumented variation involving auriculotemporal nerve, inferior alveolar nerve and middle meningeal artery. Int J Res Med Sci 2014;2:1720-2.

17. Gülekon N, Anil A, Poyraz A, Peker T, Turgut HB, Karaköse M. Variations in the anatomy of the auriculotemporal nerve. Clin Anat 2005;18:15-22.

18. Ortug G, Moriggl B. [The topography of the maxillary artery within the infratemporal fossa]. Anat Anz 1991;172:197-202. German.

19. Babu BP, Thomas H. Course of maxillary artery through loop of auriculotemporal nerve and deep to posterior division of mandibular nerve. Int J Adv Sci Eng Technol 2018;6:6-9.

20. Bronner-Fraser M. Environmental influences on neural crest cell migration. J Neurobiol 1993;24:233-47.

21. Tannahill D, Cook GM, Keynes RJ. Axon guidance and somites. Cell Tissue Res 1997;290:275-83.

22. Sanes DH, Reh TA, Harris WA. Development of the nervous system. New York: Academic Press; 2000. p. 189-97.

23. Ranscht B, Bronner-Fraser M. T-cadherin expression alternates with migrating neural crest cells in the trunk of the avian embryo. Development 1991;111:15-22.

24. Debby-Brafman A, Burstyn-Cohen T, Klar A, Kalcheim C. FSpondin, expressed in somite regions avoided by neural crest cells, mediates inhibition of distinct somite domains to neural crest migration. Neuron 1999;22:475-88.

25. Roy TS, Sarkar AK, Panicker HK. Variation in the origin of the inferior alveolar nerve. Clin Anat 2002;15:143-7.

26. Hogg ID, Stephens CB, Arnold GE. Theoretical anomalies of the stapedial artery. Ann Otol Rhinol Laryngol 1972;81:860-70.

27. Shalini R, RaviVarman C, Manoranjitham R, Veeramuthu M. Morphometric study on mandibular foramen and incidence of accessory mandibular foramen in mandibles of south Indian population and its clinical implications in inferior alveolar nerve block. Anat Cell Biol 2016;49:241-8.

28. Lee MH, Kim HJ, Kim DK, Yu SK. Histologic features and fascicular arrangement of the inferior alveolar nerve. Arch Oral Biol 2015;60:1736-41.

29. Yu SK, Kim S, Kang SG, Kim JH, Lim KO, Hwang SI, Kim HJ. Morphological assessment of the anterior loop of the mandibular canal in Koreans. Anat Cell Biol 2015;48:75-80. 